\title{
Light penetration and light intensity in sandy marine sediments measured with irradiance and scalar irradiance fiber-optic microprobes
}

\author{
Michael Kühl ${ }^{1}$, Carsten Lassen ${ }^{2}$, Bo Barker Jørgensen ${ }^{1}$ \\ ${ }^{1}$ Max Planck Institute for Marine Microbiology, Fahrenheitstr. 1, D-28359 Bremen, Germany \\ ${ }^{2}$ Department of Microbial Ecology, Institute of Biological Sciences, University of Aarhus, Ny Munkegade Building 540 , \\ DK-8000 Aarhus C, Denmark
}

\begin{abstract}
Fiber-optic microprobes for determining irradiance and scalar irradiance were used for light measurements in sandy sediments of different particle size. Intense scattering caused a maximum integral light intensity [photon scalar irradiance, $E_{0}\left(400\right.$ to $700 \mathrm{~nm}$ ) and $E_{0}(700$ to $880 \mathrm{~nm})$ ] at the sediment surface ranging from $180 \%$ of incident collımated light in the coarsest sediment (250 to $500 \mu \mathrm{m}$ grain size) up to $280 \%$ in the finest sediment $(<63 \mu \mathrm{m}$ grain size). The thickness of the upper sediment layer in which scalar irradiance was higher than the incident quantum flux on the sediment surface increased with grain size from $<0.3 \mathrm{~mm}$ in the finest to $>1 \mathrm{~mm}$ in the coarsest sediments. Below $1 \mathrm{~mm}$, light was attenuated exponentially with depth in all sediments. Light attenuation coefficients decreased with increasing particle size, and infrared light penetrated deeper than visible light in all sediments. Attenuation spectra of scalar irradiance exhibited the strongest attenuation at 450 to $500 \mathrm{~nm}$, and a continuous decrease in attenuation coefficent towards the longer wavelengths was observed. Measurements of downwelling irradiance underestimated the total quantum flux available, i.e. scalar irradiance, by $>100 \%$ throughout the sediment. Attenuation coefficents of scalar irradiance, downwelling irradiance and upwelling irradiance were, however, similar in deeper sediment layers where the light field became more diffuse. Our results demonstrate the innortance of measuring scalar irradiance when the role of light in photobiological processes in sediments, e.g. microbenthic photosynthesis, is investigated
\end{abstract}

KEY WORDS: Microscale optics $\cdot$ Scattering $\cdot$ Sediments

\section{INTRODUCTION}

Coastal sandy sediments are often inhabited by dense populations of microalgae, e.g. tidal flats can be dominated by diatoms or by microbial mats consisting chiefly of cyanobacteria and purple sulfur bacteria ('Farbstreifensandwatt') (Stal et al. 1985). The optical properties of such sediments and the associated microphytobenthos remain virtually unstudied. although light is the key parameter for microbenthic photosynthesis and its regulation. Previous studies of light penetration in sediments have been based on the use of relatively large light collectors covered by sediment layers (Hoffman 1949, Taylor 1964, Taylor \&
Gebelein 1966, Gomoiu 1967, Haardt \& Nielsen 1980) or inserted into the sediment (Fenchel \& Straarup 1971). Only recently have techniques based on fiberoptic microprobes with defined light collecting properties become available to study the light field in sediments at high spatial and spectral resolution (Jørgensen \& Des Marais 1986, Kühl \& Jørgensen 1992, Lassen et al. 1992a). By using microprobes for determining field radiance and scalar irradiance (see definitions in Table 1) the importance of scattered light in the light field in sediments was demonstrated, and basic optical parameters were calculated from measured angular radiance distributions (Kühl \& Jørgensen 1994). 
Among the surprising effects of the intense scattering on the light field was the formation of a maximum in total light intensity, i.e. scalar irradiance, in the upper 0.0 to $0.5 \mathrm{~mm}$ of the sediment reaching up to $200 \%$ of the incident light intensity at wavelengths subject to lowest absorption in the sediment. Similar observations have been made for microbial mats, where the high density of microalgal photopigments also resulted in a strong spectral alteration of the surface light field relative to incident light (Jørgensen \& Des Marais 1988, Kühl \& Jørgensen 1992, Lassen et al. 1992b). Although these studies indicate the importance of measuring scalar irradiance at a high spatial resolution the most commonly used light parameter in studies of microbenthic photosynthesis is still incident downwelling irradiance, measured with a flat cosine collector positioned at the sediment surface (e.g. Pinckney \& Zingmark 1993). It is thus important to investigate the relevance of determining the light intensity available for photosynthesis by measuring downwelling irradiance

In this study we investigated the importance of sediment particle size for the light penetration in sediments and the build-up of a near-surface maximum of scalar irradiance. Furthermore, we used a new fiber-optic microprobe for measuring irradiance, together with scalar irradiance microprobes, in order to quantify upwelling light (i.e. upwelling irradiance) and to quantify the extent to which downwelling irradiance measurements underestimate the light intensity available for photosynthesis in sediments.

\section{MATERIALS AND METHODS}

Light parameters. Definitions of the basic light parameters used in this study are given in Table 1. All parameters are a function of wavelength and can be integrated over a range of wavelengths. In this study we present photon irradiance and photon scalar irradiance data integrated from 400 to $700 \mathrm{~nm}$ (visible light, VIS or PAR) and from 700 to $880 \mathrm{~nm}$ (infrared light, IR). The fundamental light field parameter is the field radiance, which measures the radiant flux from a defined direction. From the radiance, various integral measures of light intensity can be defined. The most commonly measured light parameter is downwelling irradiance, $E_{d}$, which is the total downwelling radiant flux per unit area of a horizontal surface element. A similar measure for the upwelling light is upwelling irradiance, $E_{\mathrm{u}}$. The ratio of upwelling to downwelling irradiance is called irradiance reflectance, $R$. In most oceanic waters and

Table 1. Basic optical parameters for light measurements in sediments

\begin{tabular}{|c|c|c|c|}
\hline Parameter & Symbol & Definition & Microscale measuring technique \\
\hline Field radiance & $L(\theta, \phi)=\mathrm{d}^{2} \Phi /(\mathrm{d} A \mathrm{~d} \omega)$ & $\begin{array}{l}\text { The radiant flux, } \Phi, \text { from a } \\
\text { certain direction }(\theta, \phi) \text { in a } \\
\text { spherical coordinate system } \\
\text { per unit solid angle, } \mathrm{d} \omega, \text { per } \\
\text { unit area perpendicular to the } \\
\text { direction of light propagation, } \\
\mathrm{d} A\end{array}$ & $\begin{array}{l}\text { Measured by a simple, flat-cut } \\
\text { untapered or tapered optical fiber. } \\
\text { The radiance fiber probe has a } \\
\text { directional response defined by } \\
\text { the acceptance angle of the optical } \\
\text { fiber. Tip diameter } 10 \text { to } 125 \mu \mathrm{m} \text {. } \\
\text { (Jørgensen \& Des Marais } 1986 \text {, } \\
\text { Kühl \& Jørgensen 1992) }\end{array}$ \\
\hline $\begin{array}{l}\text { Downwelling irradiance } \\
\text { and } \\
\text { upwelling irradiance }\end{array}$ & $\begin{array}{l}E_{d}=\int_{2 \pi} L(\theta, \phi) \cos \theta \mathrm{d} \omega \\
E_{u}=\int_{-2 \pi} L(\theta, \phi) \cos \theta \mathrm{d} \omega\end{array}$ & $\begin{array}{l}\text { The integral radiant flux } \\
\text { incident from the upper or } \\
\text { lower hemisphere per unit } \\
\text { area of a horizontal surface } \\
\text { element }\end{array}$ & $\begin{array}{l}\text { Measured by a coated optical fiber } \\
\text { with a diffusing disk fixed at the } \\
\text { flat cut end of the fiber. The } \\
\text { irradiance fiber probe weights the } \\
\text { incident radiance, } L(\theta, \phi) \text {, with the } \\
\text { cosine of the incident zenith angle, } \\
\theta \text {. Tip diameter } 40 \text { to } 125 \mu \mathrm{m} \text {. } \\
\text { (C. Lassen unpubl) }\end{array}$ \\
\hline Scalar irradiance & $\begin{aligned} E_{0} & =\int_{4 \pi} L(\theta, \phi) \mathrm{d} \omega \\
& =E_{0 d}+E_{0 u}\end{aligned}$ & $\begin{array}{l}\text { The integral radiant flux } \\
\text { incident from all directions } \\
\text { about a point in the sediment. } \\
E_{0} \text { consists of a downwelling } \\
\left.\left(E_{0 d}\right) \text { and an upwelling ( } E_{0 u}\right) \\
\text { component corresponding } \\
\text { to the integral flux incident } \\
\text { from the upper or lower } \\
\text { hemisphere respectively }\end{array}$ & $\begin{array}{l}\text { Measured by a coated and tapered } \\
\text { optical fiber with a diffusing } \\
\text { sphere fixed on the tip. The fiber } \\
\text { probe has an isotropic response for } \\
\text { light incident from }+160^{\circ} \text { to }-160^{\circ} \\
\text { zenith angle. Tip diameter } 50 \text { to } \\
100 \mu \mathrm{m} \text {. (KühI \& Jørgensen } 1992 \\
\text { Lassen et al. 1992a) }\end{array}$ \\
\hline
\end{tabular}



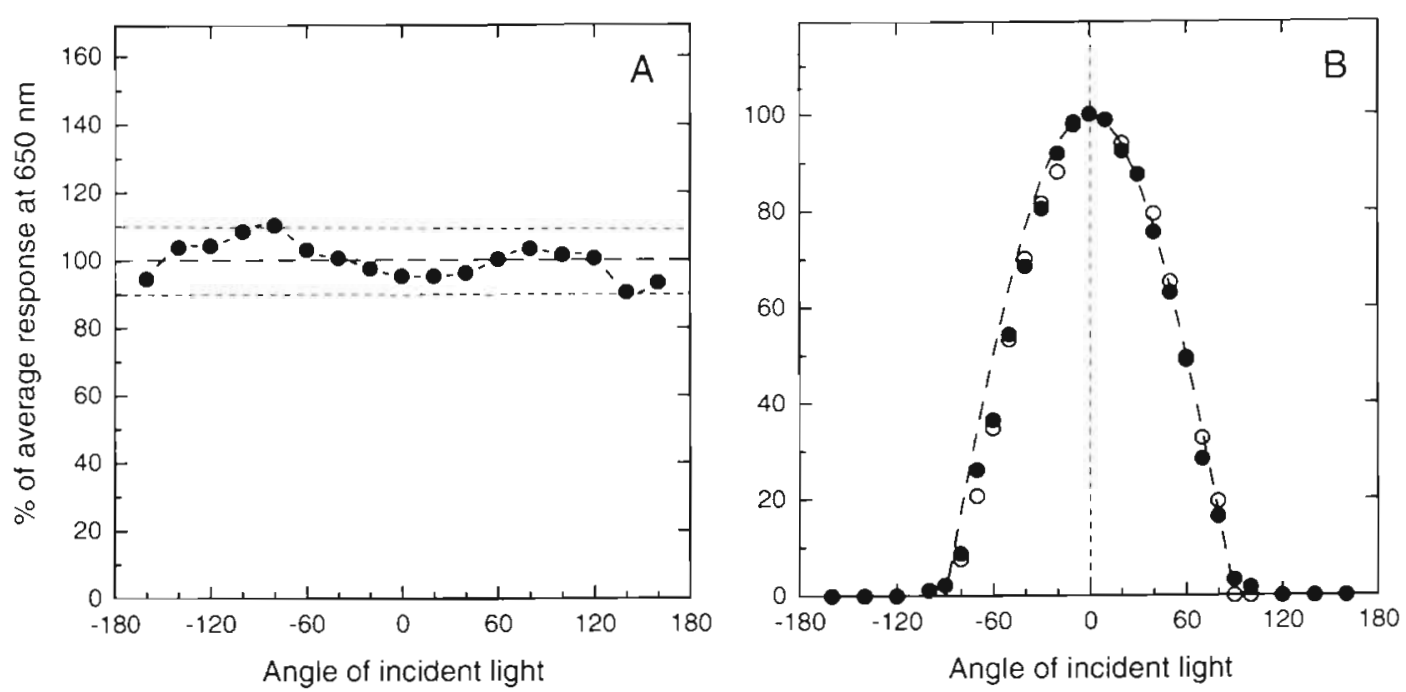

Fig. 1 Light collecting properties of fiber-optic microprobes for scalar irradiance (A; sphere diameter $80 \mu \mathrm{m}$ ) and irradiance ( $B$; tip diameter $125 \mu \mathrm{m}$ ) measured by rotating the fiber probe relative to a collimated light beam with the tip fixed at the same position and distance relative to the light source. The acceptance function of the irradiance probe was determined at 2 different orientations (solid and open symbols) by rotating the fiber $90^{\circ}$ after the first series of measurements. Thick dotted lines represent the theoretical response of an ideal scalar irradiance and irradiance sensor respectively

clear coastal waters the irradiance reflectance is only a few percent, and the light field is highly forwarddirected (Jerlov 1976, Kirk 1983). Downwelling irradiance is thus an appropriate light intensity parameter to measure in combination with photosynthesis measurements in the water column of clear waters. In turbid waters and near the sea floor, irradiance reflectance can increase up to $20-30 \%$ as the light field becomes more diffuse due to higher scattering intensity (Kirk 1983). In sediments this effect is even more pronounced due to the high density of scattering material (Kühl \& Jørgensen 1994). In turbid waters and sediments irradiance measurements thus underestimate the total quantum flux available for phototrophs. Furthermore, irradiance weights incident radiance with the cosine of the incident angle (see Table 1) and thus weights scattered light travelling at an oblique angle less than directional collimated light. Sediment microalgae live, however, in a highly diffuse light field and receive light from all directions around the cells (Jørgensen \& Des Marais 1988, Kühl \& Jørgensen 1994). The scalar irradiance, $E_{0}$, is an integral measure of light incident from all directions about a point and thus quantifies the total amount of light available for photosynthesis at a given depth. Scalar irradiance is therefore the most relevant light parameter to measure in combination with studies of microbenthic photosynthesis.

Fiber-optic microprobes. Fiber-optic microprobes for measuring irradiance and scalar irradiance were developed in our laboratory. The scalar irradiance microprobe had an isotropic $( \pm 10 \%$ ) response for light incident from $-160^{\circ}$ to $+160^{\circ}$ (Fig. $1 \mathrm{~A}$ ) and consisted of a small diffusing sphere $(80 \mu \mathrm{m}$ diameter $)$ cast on the coated tip of a tapered optical fiber (Lassen et al. 1992a). The irradiance microprobe was made by fixing a small diffusing disk of $\mathrm{TiO}_{2}$-doped methacrylate on the end of an untapered optical fiber (tip diameter $125 \mu \mathrm{m})$, which was coated on the sides with black enamel paint. The angular response of the irradiance microprobe closely matched the theoretical response curve for a cosine collector (Fig. 1B). A description of the manufacturing procedure of irradiance microprobes and their light collecting properties is given elsewhere (Lassen unpubl.).

Experimental setup. Light penetration was measured in quartz sand of different grain sizes. Sediment was collected at the upper littoral zone at a beach near Rønbjerg, Limfjorden, Denmark, and was sieved into particle sizes of $<63,63-125,125-250$, and 250-500 $\mu \mathrm{m}$. Animals and organic material adherent to the sand grains were removed by washing, and the sand was dried at $105^{\circ} \mathrm{C}$ before use. Light measurements were done in 7 to $8 \mathrm{~mm}$ thick sediment samples transferred to black coring tubes, which were sealed at the bottom with a plug of solidified agar. Measurements in wet material were done with 3 to $5 \mathrm{~mm}$ of water on top of the sediment. Homogeneous vertical illumination was provided by a fiber-optic tungstenhalogen light source (Schott KL-1500, Germany) equipped with a collimating lens. A detailed description of the measuring setup is given elsewhere (Kühl \& Jørgensen 1992, 1994). Microscale spectral light measurements were done at a spatial resolution of $0.1 \mathrm{~mm}$ 
using fiber-optic microprobes for irradiance and scalar irradiance connected to an optical multichannel analyser (Kühl \& Jørgensen 1992, Lassen et al. 1992a). The position of the microprobes was controlled by a motorized micromanipulator (Märtzhäuser, Germany) interfaced to a computer via a custom-built controller card and software. Depth profiles of spectral scalar irradiance, $E_{0}$, were measured by inserting the scalar irradiance microprobe into the sediment from above at a zenith angle of $135^{\circ}$ relative to the incident collimated light beam. Depth profiles of spectral downwelling irradiance, $E_{\mathrm{d}}$, and upwelling irradiance, $E_{u}$, were measured by inserting the irradiance microprobe from below through the agar plug at $0^{\circ}$ zenith angle and from above at $175^{\circ}$ zenith angle respectively. Integrated values for VIS (400 to $700 \mathrm{~nm}$ ) and IR ( 700 to $880 \mathrm{~nm}$ ) photon irradiance or photon scalar irradiance were obtained by integrating measured spectra corrected for the spectral sensitivity of the detector system (Kühl \& Jørgensen 1992, Lassen et al. 1992b).

Attenuation coefficients. The diffuse vertical attenuation coefficient, $K$, for irradiance or scalar irradiance is defined as:

$$
K=-\frac{\mathrm{d} \ln E}{\mathrm{~d} z}=-\frac{1}{E} \frac{\mathrm{d} E}{\mathrm{~d} z}
$$

where $z=$ depth. Attenuation coefficients for downwelling irradiance, $K_{\mathrm{d}}$, upwelling irradiance, $K_{\mathrm{u}}$, and scalar irradiance, $K_{0}$, were calculated in 2 ways. Attenuation coefficients for integral VIS or IR irradiance and scalar irradiance were calculated by linear regression from the slope of linear parts of ln-transformed depth profiles, i.e. equivalent to the right hand side of Eq. (1). Attenuation spectra of scalar irradiance were furthermore calculated over a sediment layer of 0.5 to $1.5 \mathrm{~mm}$ by the formula:

$$
K=\frac{\ln \left(E_{1} / E_{2}\right)}{z_{1}-z_{2}}
$$

using the spectral irradiance or scalar irradiance, $E$, measured at depths $z_{1}$ and $z_{2}$, in the sediment, where $z_{2}>z_{1}$. All attenuation coefficients presented here have the unit $\mathrm{mm}^{-1}$.

\section{RESULTS}

\section{Comparison of irradiance and scalar irradiance}

Depth profiles of downwelling irradiance, $E_{\mathrm{d}}$, and of scalar irradiance, $E_{0}$, in wet quartz sand of 125 to $250 \mu \mathrm{m}$ particle size are shown in Fig. 2. At the sediment surface the incident light was collimated and the downwelling irradiance was thus equal to the downwelling scalar irradiance at the sediment surface. The

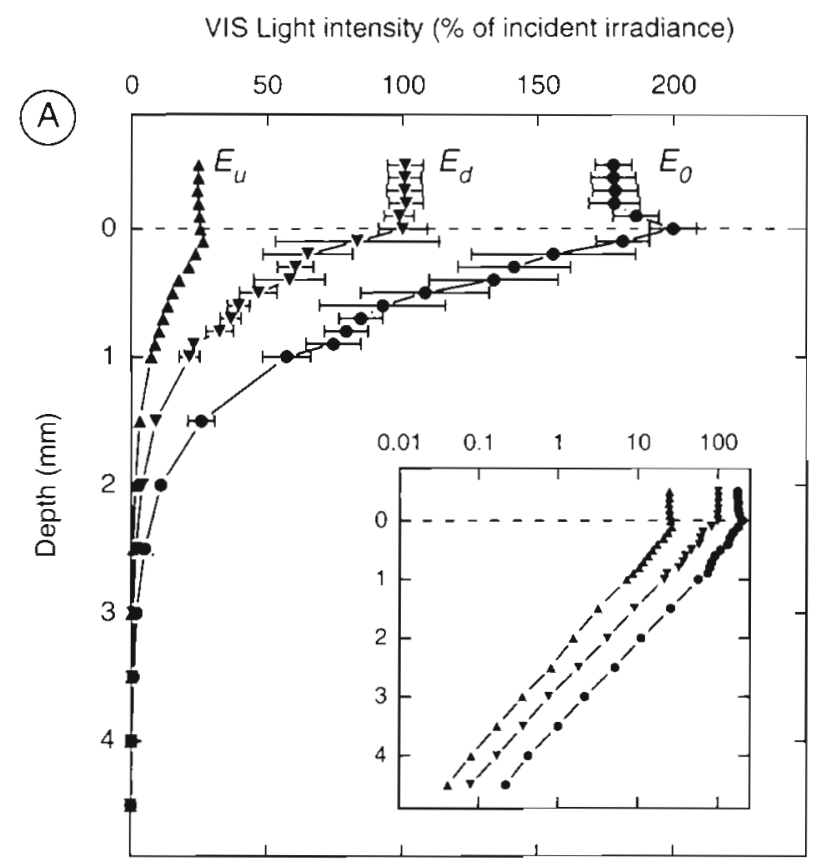

IR Light intensity (\% of incident irradiance)

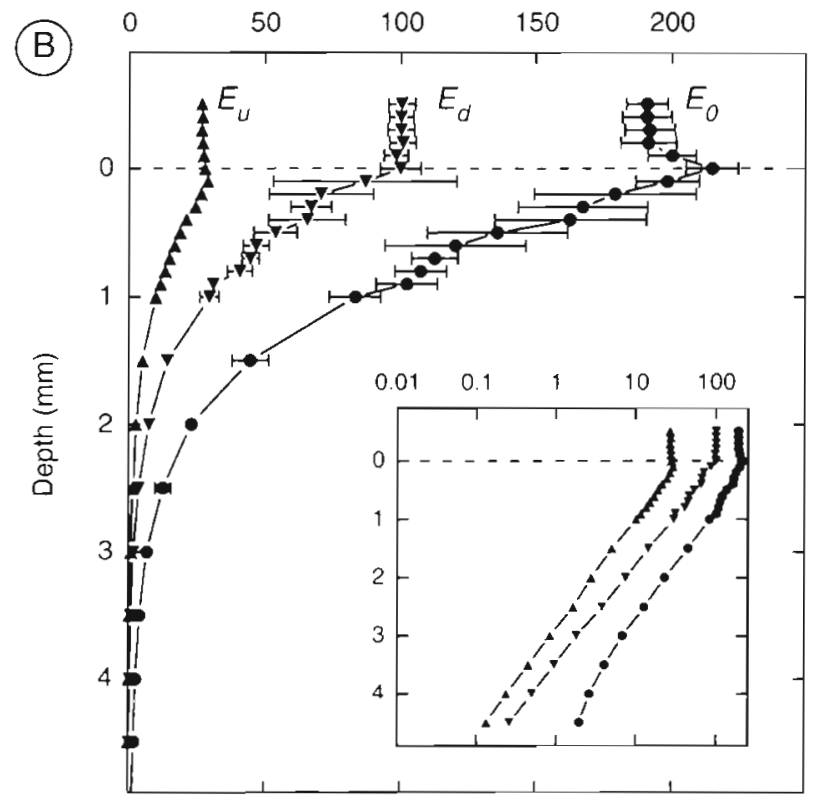

Fig. 2. Depth profiles of (A) VIS (400-700 nm) light and (B) IR $(700-880 \mathrm{~nm})$ light, in wet quartz sand (particle size 125 to $250 \mu \mathrm{m}$ ). Light intensity measured as downwelling irradiance, $E_{d}(\boldsymbol{\nabla})$, upwelling irradiance, $E_{u}(\mathbf{4})$, and scalar irradiance, $E_{0}(\bullet)$. Insets show depth profiles of log transformed data. Light intensities are expressed as \% of incident collimated light at the sediment surface $\left[E_{0 d}\right.$ (surface) = $E_{\mathrm{d}}($ surface)]. Error bars indicate the standard deviation and data points represent the arithmetic mean of 3 to 5 measurements 
Table 2. Attenuation coefficients ( \pm SD) of VIS and IR light in wet and dry quartz sand (particle size 125 to $250 \mu \mathrm{m}$ )

\begin{tabular}{|c|c|c|c|}
\hline \multirow[t]{2}{*}{ Sediment } & \multicolumn{3}{|c|}{ Attenuation coefficients } \\
\hline & $\begin{array}{l}\text { Downwelling } \\
\text { irradiance, } K_{\mathrm{d}}\end{array}$ & $\begin{array}{l}\text { Upwelling } \\
\text { irradiance, } K_{u}\end{array}$ & $\begin{array}{c}\text { Scalar } \\
\text { irradiance, } K_{0}\end{array}$ \\
\hline \multicolumn{4}{|l|}{ Dry sand } \\
\hline VIS light $(400-700 \mathrm{~nm})$ & $2.73( \pm 0.05)$ & $2.71( \pm 0.04)$ & $2.65( \pm 0.09)$ \\
\hline IR light $(700-880 \mathrm{~nm})$ & $2.42( \pm 0.05)$ & $2.43( \pm 0.03)$ & $1.94( \pm 0.09)$ \\
\hline \multicolumn{4}{|l|}{ Wet sand ${ }^{a}$} \\
\hline VIS light $(400-700 \mathrm{~nm})$ & $1.61( \pm 0.04)$ & $1.46( \pm 0.02)$ & $1.59( \pm 0.02)$ \\
\hline IR light $(700-880 \mathrm{~nm})$ & $1.36( \pm 0.03)$ & $1.22( \pm 0.01)$ & $1.21( \pm 0.02)$ \\
\hline
\end{tabular}

Table 3. Attenuation coefficients $\left(K_{0}, \pm \mathrm{SD}\right)$ of VIS and IR scalar irradiance in wet quartz sand of different particle size. $K_{0}$ was calculated from log-linear parts of depth profiles in Fig. $3\left(\mathrm{r}^{2}>0.99\right)$

\begin{tabular}{|lcccc|}
\hline & & \multicolumn{2}{c|}{ Particle size } \\
\hline VIS light $(400-700 \mathrm{~nm})$ & $3.46( \pm 0.02)$ & $63-125 \mu \mathrm{m}$ & $125-250 \mu \mathrm{m}$ & $250-500 \mu \mathrm{m}$ \\
IR light $(700-880 \mathrm{~nm})$ & $2.84( \pm 0.02)$ & $1.64( \pm 0.02)$ & $1.60( \pm 0.02)$ & $0.99( \pm 0.03)$ \\
\hline
\end{tabular}

total light intensity, i.e. the scalar irradiance, was, however, much higher. For VIS and IR light, scalar irradiance exhibited a distinct maximum of $200 \%$ and $215 \%$ of the incident irradiance at the sediment surface, respectively. Throughout the sediment, scalar irradiance was $>2 \times$ higher than the downwelling irradiance measured at the same depths.

The upwelling VIS and IR irradiance, $E_{u}$, in wet quartz sand is also shown in Fig. 2. The upwelling light was a significant component of the total light intensity and upwelling irradiance was on the order of 20 to $40 \%$ of the downwelling irradiance at corresponding depths in the sediment. As the data were normalised to the incident downwelling irradiance, the surface value of $E_{\mathrm{u}}$ corresponds to the surface irradiance reflectance, $R=E_{\mathrm{u}} / E_{\mathrm{d}}$. Surface irradiance reflectance, also called the albedo of the sediment, was $25 \%$ and $28 \%$ for VIS and IR light respectively. From a similar data set in dry quartz sand (data not shown), sediment albedos of $35 \%$ and $40 \%$ for VIS and IR light were calculated.

The depth profiles of upwelling and downwelling irradiance as well as scalar irradiance showed an exponential light attenuation with depth below $1 \mathrm{~mm}$ in the wet quartz sand (see insets in Fig. 2), with similar diffuse attenuation coefficients (Table 2). In dry quartz sand of the same particle size we found a higher attenuation of VIS and IR light than in the wet sand (Table 2 ; depth profiles not shown). In both cases VIS light was attenuated more strongly than IR light.

\section{Scalar irradiance as a function of particle size}

Depth profiles of VIS and IR scalar irradiance in wet sediment with different grain sizes are shown in Fig. 3. In all sediments a pronounced surface maximum of scalar irradiance was found. The surface maximum of scalar irradiance increased, while the light penetration decreased, with decreasing particle size. IR light exhibited both a higher surface maximum of scalar irradiance and deeper light penetration than VIS light in all sediments. Highest values of scalar irradiance maxima were found in wet quartz sand of $<63 \mu \mathrm{m}$ particle size, where the VIS and IR scalar irradiance reached up to $260 \%$ and $280 \%$ of the incident light intensity respectively. The near-surface zone of the sediment, where scalar irradiance values were higher than the incident irradiance, varied in thickness from $<0.3 \mathrm{~mm}$ in the finest to $>1 \mathrm{~mm}$ in the coarsest sediment. Light $\left(E_{0}\right)$ was attenuated exponentially with depth starting from the surface in the finest sediment $(<63 \mu \mathrm{m})$, while exponential attenuation of light started below a depth of $0.5 \mathrm{~mm}$ in 63 to $125 \mu \mathrm{m}$ sand, $1 \mathrm{~mm}$ in 125 to $250 \mu \mathrm{m}$ sand, and $>1 \mathrm{~mm}$ in 250 to $500 \mu \mathrm{m}$ sand. The attenuation coefficient of scalar irradiance increased with decreasing particle size of the sediment (Table 3). Attenuation coefficients of the 63 to $125 \mu \mathrm{m}$ and the 125 to $250 \mu \mathrm{m}$ sediment were almost identical as both sediment types had their major grain size fraction near $125 \mu \mathrm{m}$. 
VIS scalar irradiance ( $\%$ of incident irradiance)

(A)

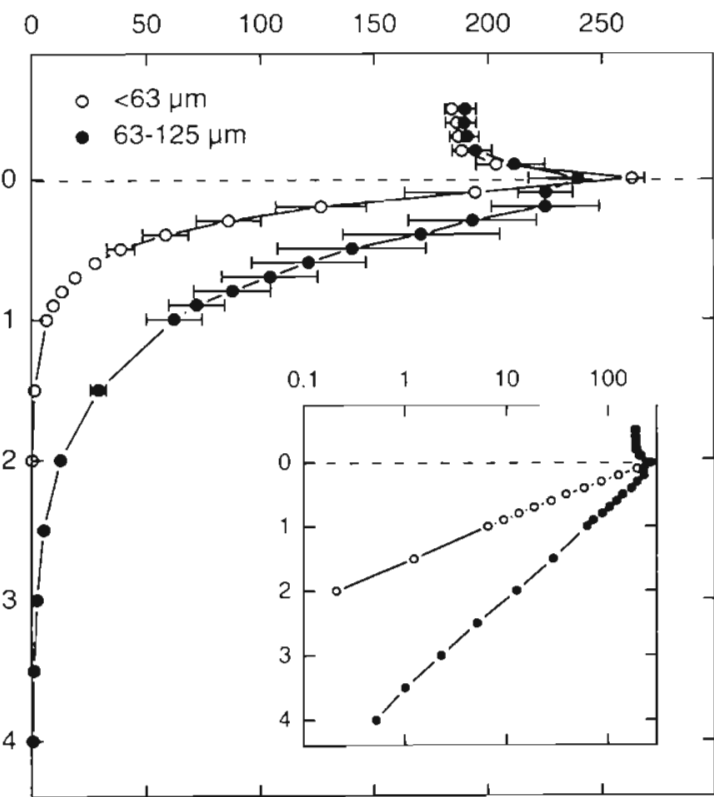

VIS scalar irradiance (\% of incident irradiance)

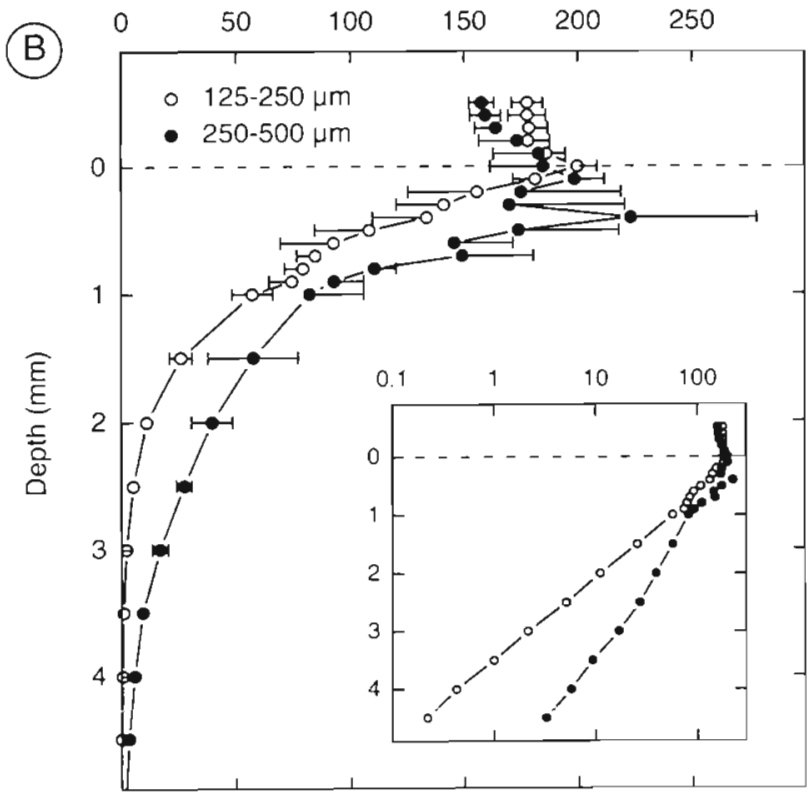

IR scalar irradiance (\% of incident irradiance)

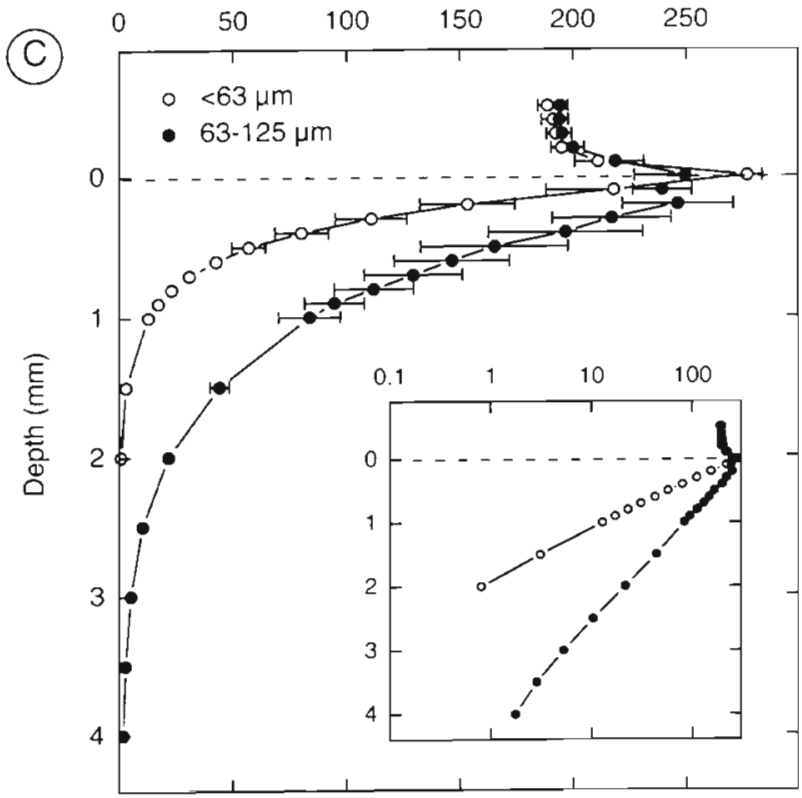

IR scalar irradiance (\% of incident irradiance)

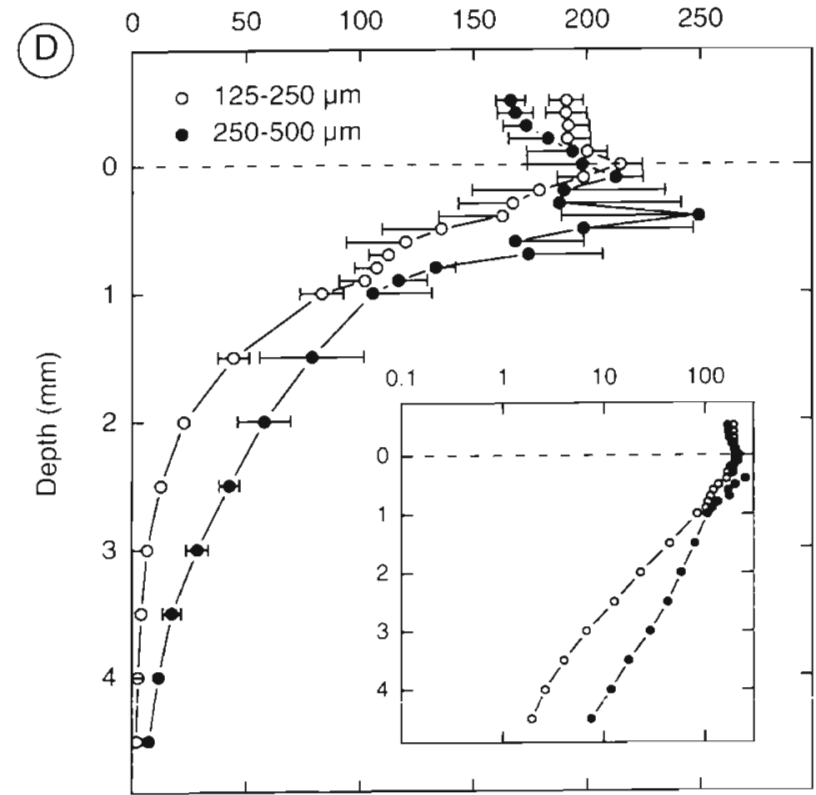

Fig. 3. Depth profiles of (A, B) VIS (400 to $700 \mathrm{~nm})$ and (C, D) IR (700 to $880 \mathrm{~nm}$ ) scalar irradiance in wet quartz sand of different particle size. Light intensities are expressed as \% of incident collimated light at the sediment surface [ $E_{0 \mathrm{~d}}($ surface $)=E_{\mathrm{d}}($ surface)]. Error bars indicate the standard deviation and data points represent the arithmetic mean of 3 to 5 measurements

The spectral attenuation of scalar irradiance in sediments of different grain size is shown in Fig. 4. In all sediments, 450 to $500 \mathrm{~nm}$ light was attenuated most strongly, and the attenuation coefficients decreased continuously towards longer wavelengths, with IR light exhibiting the lowest attenuation. This spectral variation in attenuation coefficient was most pronounced in the $<63 \mu \mathrm{m}$ grain size sediment and gradually decreased in the coarser sediments. 


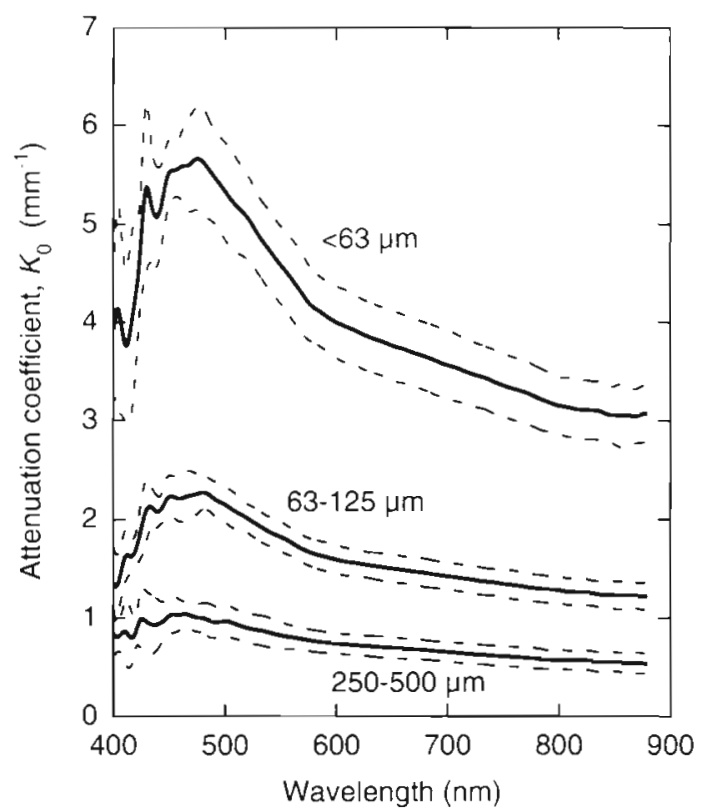

Fig. 4. Attenuation spectra of scalar irradiance, $E_{0}$, in quartz sand of 3 different particle sizes. The spectra represent the mean of 3 to 5 measurements (continuous lines) \pm SD (dotted lines)

\section{DISCUSSION}

\section{Heterogeneity of the light field}

Light measurements with fiber-optic microprobes have the advantage of high spatial resolution, enabling the characterisation of the light field on the same scale at which microbenthic photosynthesis can be quantified by microelectrodes (Revsbech \& Jorgensen 1983). This, however, results in inherent problems with heterogeneous sediment structure, which makes repetitive measurements necessary. Thus, due to the small size of the fiber probes, measurements at the sediment surface depend on the sediment structure and microtopography, and the measurement resolution cannot be much better than half the average grain size of the sediment. The depth profiles of irradiance and scalar irradiance presented in this study exhibited the highest variability, i.e. the highest standard deviation, in the upper $\mathrm{mm}$ of the sediment (Figs. $2 \& 3$ ). In this near-surface layer interactions with individual sand grains, for example the presence of a transparent (quartz) or a coloured (e.g. felspar) sand grain at the probe tip, can cause large variations in the detected light intensity. There may also be a slight physical disturbance of the sediment due to penetration by the fiber probe. The described effects were most pronounced in the coarsest sediment, which exhibited a relative standard deviation of scalar irradiance of \pm 20 to $25 \%$ near the surface. The relative standard deviations of the measured light intensities near the sediment surface decreased with particle size and were $\pm 15 \%$ in the finest sediment. In deeper sediment layers the standard deviation was generally lower as the intense scattering of light smoothed out effects of nearsurface heterogeneities in the light field.

\section{Sediment optics}

We found surface maxima of photon scalar irradiance ranging from $180 \%$ of incident irradiance in the coarsest sediment ( 250 to $500 \mu \mathrm{m}$ grain size) up to $280 \%$ in the finest sediments (<63 $\mu \mathrm{m}$ grain size) where scattering was most intense (Fig. 3). Although the measurements in pure sand represent an extreme situation, with high scattering intensity and little absorption, similar scalar irradiance maxima have also been calculated from measured radiance distributions or have been measured directly in microbial mats and biofilms (e.g. Jørgensen \& Des Marais 1988, Lassen et al. 1992b, Kühl 1993, Kühl \& Jørgensen 1994) as well as in plant and animal tissue (e.g. Vogelmann \& Björn 1984, Star et al, 1987, Profio 1989). A near-surface maximum of scalar irradiance thus seems to be an inherent property of compact lightscattering media in which multiple scattering is important for the radiative transfer.

Although a build-up of light intensity to $>100$ to $200 \%$ of incident light intuitively may appear to be in conflict with the laws of thermodynamics, this phenomenon can be explained by the internal reflection and refraction properties of scattering media (e.g. Vogelmann \& Björn 1986, Kaufmann \& Hartmann 1988, Anderson et al. 1989). Light attenuation in sediments is due to both absorption and multiple scattering, where scattering enhances the probability of absorption. If absorption is low, however, strong scattering maintains a high flux density at a given depth in the sediment (i.e. light is travelling a longer distance per vertical distance traversed). This effect of multiple scattering is especially enhanced near optical boundaries, e.g. the sediment-water interface or interfaces between different layers in a sediment, where differences in refractive index could result in internal reflection at the boundaries. This results in apparent light trapping phenomena such as the local maximum of light intensity relative to the incident light from above. A more detailed discussion of the optical mechanisms behind the observed scalar irradiance maximum can be found elsewhere (e.g. Vogelmann \& Björn 1986 , Kaufmann \& Hartmann 1988, Anderson et al. 1989, Seyfried 1989, Kühl \& Jørgensen 1994).

In the investigated sandy sediments, scattering predominated and resulted in a significant amount of 
upwelling light as seen from the depth profiles of upwelling irradiance (Fig. 2). The sediments exhibited a high irradiance reflectance of 20 to $40 \%$. In dry sand a higher irradiance reflectance was found than in wet sand, accompanied by a stronger light attenuation in dry sand (Table 2). Similar results were obtained by calculating irradiance reflectance from measured radiance distributions in the same type of sediment (Kühl \& Jørgensen 1994). A higher reflectance and light attenuation in dry versus wet sand is due to a change in the scattering properties of the sand particles upon wetting (Bohren 1983, Twomey et al. 1986). Light scattering in sand becomes more forward-directed, and light thus penetrates deeper when the difference in refractive index between the quartz particles and the surrounding medium is lowered by wetting. Light must therefore travel a longer distance, i.e. be scattered more times, before being redirected towards the surface (Bohren 1983). Increasing the light path does, however, also increase the probability of absorption of upwelling light, thus resulting in a lower reflectance of wet sediments.

Measurements of spectral irradiance reflectance, $R$, can be used to describe the spectral scalar irradiance at the sediment surface from measurements of spectral. downwelling irradiance. Kühl \& Jørgensen (1994) found a good approximation to measured scalar irradiance values for single wavelengths, $\lambda$, at the sediment surface, $z_{0}$, by using the simple model of Anderson et al. (1989):

$$
E_{0}\left(z_{0}, \lambda\right)=E_{\mathrm{d}}\left(z_{0}, \lambda\right)\left[1+2 R\left(z_{0}, \lambda\right)\right]
$$

Surface photon scalar irradiance for VIS and IR light calculated by Eq. (3) from the measured irradiances in this study was $150 \%$ and $156 \%$ of downwelling irradiance in wet quartz sand, while directly measured values reached $200 \%$ and $215 \%$ of downwelling VIS and IR irradiance, respectively. The use of Eq. (3) for integral measurements of VIS and IR light is thus inappropriate as it does not take the spectral variation of light attenuation within the VIS and IR range into account.

The strong light attenuation in sediments is the combined result of absorption and multiple scattering of light. Near the sediment surface the light field is highly anisotropic and consists mainly of collimated light from above and diffuse scattered light from below (Kühl \& Jorgensen 1994). With increasing depth in the sediment, the collimated light is scattered, and the light field thus becomes more diffuse and can finally approach an asymptotic state, where the spatial light distribution no longer changes with depth and the attenuation coefficents of radiance, irradiance, and scalar irradiance thus become identical. The depth profiles of irradiance and scalar irradiance presented in this study confirm these fundamental properties of the light field, which have also been determined from measured radiance distributions in similar sediments (see Kühl \& Jørgensen 1994). The near-surface zone, where the anisotropic light field changes with depth, had a thickness of $<1 \mathrm{~mm}$ in sand of 125 to $250 \mu \mathrm{m}$ particle size. Below this depth the attenuation coefficients of photon irradiance and photon scalar irradiance became almost identical (Fig. 2, Table 2) indicating a diffuse and near-asymptotic light field

An increasing scattering intensity with decreasing sediment particle size resulted in a higher attenuation of light in the fine grained sediments (Figs. $3 \& 4$, Table 3). At the same time, however, the increased scattering intensity resulted in a higher surface maximum of scalar irradiance and a narrower anisotropic zone in the fine grained sediments (Fig. 3). Light attenuation in the sediments was generally highest for blue light, probably due to the presence of iron oxides and coloured sand grains in the sediments (Fig. 4). The spectral variation in the attenuation of scalar irradiance was most pronounced in the fine grained sediment, although the absorption was expected to be more or less independent of particle size (Fig. 4). With decreasing particle size the scattering intensity is increased, resulting in a longer pathlength travelled by the photons in order to penetrate a certain vertical distance into the sediment. Photons are thus scattered more times and, as there is a given probability for absorption at each encounter with a sediment particle, the overall result is a higher attenuation of light even though the absorption properties of the sediment have not changed. This mechanism will be most pronounced at wavelengths which are absorbed most strongly by the sediment. Increased multiple scattering thus tends to amplify relatively small spectral variations of absorption in sandy sediments.

\section{Measurement of light intensity in sediments}

This study presents the first comparison of direct microscale measurements of irradiance and scalar irradiance in sediments. The results demonstrate the importance of choosing the correct light parameter in studies of benthic photobiology. Measurements of downwelling photon irradiance, which is the most commonly measured light parameter in benthic studies, can underestimate the total light intensity, i.e. the scalar irradiance, in the sediment by $>100 \%$, for both visible and infrared light. Although this represents an extreme value measured in scattering sand with little absorption, similar results have been obtained in other sediments or biofilms exhibiting much higher light absorption. Visible photon scalar irradiance measure- 
ments in coastal sediments covered by cyanobacteria or diatoms showed a maximum light intensity of 120 to $130 \%$ of incident irradiance at the mat surface (Lassen et al. 1992b). In a laminated coastal sandy sediment ('Farbstreifensandwatt'; Stal et al. 1985), visible photon scalar irradiance was higher than incident irradiance in the upper $0.4 \mathrm{~mm}$ of the sediment, with a surface maximum of $120 \%$ of incident irradiance (Kühl \& Jørgensen 1992). Even in a very dense cyanobacterial biofilm without significant amounts of light-scattering mineral particles, photon scalar irradiance was $120 \%$ of the incident downwelling irradiance at the biofilm surface (Kühl 1993) The values mentioned represent integral light intensities for 400 to $700 \mathrm{~nm}$ light, i.e. VIS photon scalar irradiance. Spectral scalar irradiance measurements have shown even higher maxima ranging from $120 \%$ for blue light to $>200 \%$ for IR light in coastal marine sediments and microbial mats (Kühl \& Jørgensen 1992, Lassen et al. 1992b). Therefore, in detailed studies of the regulatory role of light for microbenthic photosynthesis, measurements of scalar irradiance at high spatial resolution are essential. The photosynthetic performance of the microphytobenthos should thus be related to the scalar irradiance when measuring light saturation curves (P-I curves) or action spectra of photosynthesis (Jørgensen et al. 1987, Ploug et al. 1993).

In conclusion, the use of the fiber-optic microprobes described here, in combination with oxygen microelectrodes, now makes it possible to investigate sediment optics, microbenthic photosynthesis, and the photophysiology of benthic photosynthetic microorganisms at a level comparable to that of aquatic optics and plankton research.

Acknowledgements. This study was supported by the Carlsberg Foundation (Denmark), the Danish Center for Environmental Biotechnology, the Danish Natural Science Research Council, and the Max Planck Society (Germany).

\section{LITERATURE CITED}

Anderson, R. R., Beck, H., Bruggemann, U., Farinelli, W., Jaques, S. L., Parrish, J. A. (1989). Pulsed photothermal radiometry in turbid media: internal reflection of backscattered radiation strongly influences optical dosimetry. Appl. Optics 28: 2256-2262

Bohren, C. F. (1983). Multiple scattering at the beach. Weatherwise 36: 197-200

Fenchel, T. M., Straarup, B. J. (1971). Vertical distribution of photosynthetic pigments and the penetration of light in marine sediments. Oikos 22: 172-182

Gomoiu, M. T (1967). Some quantitative data on light penetration in sediments. Helgoländer wiss. Meeresunters. 15: $120-127$

Haardt, H., Nielsen, G. Æ. (1980). Attenuation measurements of monochromatic light in marine sediments. Oceanol. Acta 3: $333-338$
Hoffman, C. (1949). Über die Durchlässigkeit dünner Sandschichten für Licht. Planta 36: 48-56

Jerlov, N. G. (1976). Marine optics. Elsevier, Amsterdam

Jørgensen, B. B., Cohen, Y., Des Marais, D. J. (1987). Photosynthetic action spectra and adaptation to spectral light distribution in a benthic cyanobacterial mat. Appl environ. Microbiol. 53: 879-886

Jørgensen, B. B., Des Marais, D. J. (1986). A simple fiber-optic microprobe for high resolution light measurements: application in marine sediment. Limnol. Oceanogr. 31: $1376-1383$

Jørgensen, B. B., Des Marais, D. J. (1988). Optical properties of benthic photosynthetic communities: fiber-optic studies of cyanobacterial mats. Limnol. Oceanogr. 33: 99-113

Kaufmann, W. F., Hartmann, K. W. (1988). Internal brightness of disk-shaped samples. J. Photochem. Photobiol. 1: $337-360$

Kirk, J. T O. (1983). Light and photosynthesis in aquatic ecosystems. Cambridge University Press, Cambridge

Kuhl, M. (1993). Photosynthesis, $\mathrm{O}_{2}$ respiration and sulfur cycling in a cyanobacterial biofilm. Proceedings of the 6 th International Symposium on Microbial Ecology, Barcelona 1992 (in press)

Kühl, M., Jørgensen, B. B. (1992). Spectral light measurements in microbenthic phototrophic communities with a fiber-optic microprobe coupled to a sensitive diode array detector. Limnol. Oceanogr. 37: 1813-1823

Kühl, M., Jørgensen, B. B. (1994). The light field of microbenthic communities: radiance distribution and microscale optics of sandy coastal sediments. Limnol. Oceanogr. (in press)

Lassen, C., Ploug, H., Jørgensen, B. B. (1992a). A fibre-optic scalar irradiance microsensor: application for spectral light measurements in sediments. FEMS Microbiol. Ecol. 86: $247-254$

Lassen, C., Ploug, H., Jørgensen, B. B. (1992b). Microalgal photosynthesis and spectral scalar irradiance in coastal marine sediments of Limfjorden, Denmark. Limnol. Oceanogr. 37: 760-772

Pinckney, J., Zingmark, R. G. (1993). Photophysiological responses of intertidal benthic microalgal communities to in situ light environments: methodological considerations. Limnol. Oceanogr. $38(8)$ : in press

Ploug, H., Lassen, C., Jørgensen, B. B. (1993). Action spectra of microalgal photosynthesis and depth distribution of spectral scalar irradiance in a coastal sediment of Limfjorden, Denmark. FEMS Microbiol. Ecol. 102: $261-270$

Profio, A. E. (1989). Light transport in tissue. Appl. Optics 28: $2216-2222$

Revsbech, N. P., Jørgensen, B. B. (1983). Photosynthesis of benthic microflora measured with high spatial resolution by the oxygen microprofile method: capabilities and limitations of the method. Limnol. Oceanogr. 28: 749-756

Seyfried, M. (1989). Optical radiation interactions with living tissue. In: Diffey, B. L. (ed.) Radiation measurement in photobiology. Academic Press, London, p. 191-223

Stal, L. J. H., van Gemerden, H., Krumbein, W. E. (1985). Structure and development of a benthic marine microbial mat. FEMS Microbiol. Ecol. 31: 111-125

Star, W. M., Marijnissen, J. P. A., van Gemert, M. J. C. (1987). Light dosimetry: status and prospects. J. Photochem. Photobiol. Ser. B. 1: 149-167

Taylor, W. R. (1964). Light and photosynthesis in intertidal benthic diatoms. Helgoländer wiss. Meeresunters. 10: $29-37$

Taylor, W. R., Gebelein, C. D. (1966). Plant pigments and light 
penetration in intertidal sediments. Helgoländer wiss. Meeresunters. 13: 229-237

Twomey, S. A., Bohren, C. F., Mergenthaler, J. L. (1986). Reflectance and albedo differences between wet and dry surfaces. Appl. Optics 25: 431-437

This article was submitted to the editor
Vogelmann, T. C., Björn, L. O. (1984). Measurements of light gradients and spectral regime in plant tissue with a fiber optic probe. Physiol. Plant. 60: 361-368

Vogelmann, T. C., Björn, L. O. (1986). Plants as light traps. Physiol. Plant. 68: 704-708

Manuscript first received: September 6, 1993 Revised version accepted: November 8, 1993 